\title{
Intrinsic Religiousness and Spirituality as Predictors of Mental Health and Positive Psychological Functioning in Latter-Day Saint Adolescents and Young Adults
}

\author{
Kawika Allen \\ Brigham Young University, gekawika_allen@byu.edu \\ Peter W. Sanders \\ Brigham Young University, peter_sanders@byu.edu \\ P. Scott Richards \\ Brigham Young University, scott_richards@byu.edu \\ Lane Fischer

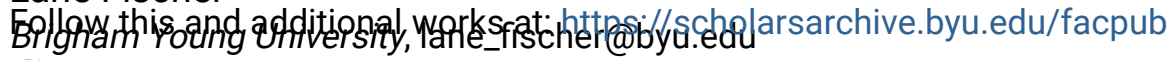 \\ Part of the Mental and Social Health Commons \\ David T. Morgan \\ Brigham Young University \\ Original Publication Citation
}

Sanders, P. W., Allen, G. E. K., Fischer, L., Richards, P. S., *Morgan, D. T., \& *Potts, R. W. (2015).


functioning in Latter-day Saint adolescents and young adults. Journal of Religion and Health, 54(3), 871-887

\section{BYU ScholarsArchive Citation}

Allen, Kawika; Sanders, Peter W.; Richards, P. Scott; Fischer, Lane; Morgan, David T.; and Potts, Richard W., "Intrinsic Religiousness and Spirituality as Predictors of Mental Health and Positive Psychological Functioning in Latter-Day Saint Adolescents and Young Adults" (2015). Faculty Publications. 3173. https://scholarsarchive.byu.edu/facpub/3173

This Peer-Reviewed Article is brought to you for free and open access by BYU ScholarsArchive. It has been accepted for inclusion in Faculty Publications by an authorized administrator of BYU ScholarsArchive. For more information, please contact ellen_amatangelo@byu.edu. 


\section{Authors}

Kawika Allen, Peter W. Sanders, P. Scott Richards, Lane Fischer, David T. Morgan, and Richard W. Potts 


\title{
Intrinsic Religiousness and Spirituality as Predictors of Mental Health and Positive Psychological Functioning in Latter-Day Saint Adolescents and Young Adults
}

\author{
Peter W. Sanders ${ }^{1}$ - G. E. Kawika Allen ${ }^{1}$ - Lane Fischer ${ }^{1}$. \\ P. Scott Richards ${ }^{1} \cdot$ David T. Morgan ${ }^{1} \cdot$ Richard W. Potts $^{1}$
}

Published online: 9 April 2015

(C) Springer Science+Business Media New York 2015

\begin{abstract}
We investigated the relationships between religiousness and spirituality and various indicators of mental health and positive psychosocial functioning in three separate samples of college students. A total of 898 students at Brigham Young University participated in the three studies. The students ranged in age from 17 to 26 years old, with the average age of 20.9 across all three samples. Our results indicate that intrinsic religiousness, spiritual maturity, and self-transcendence were significantly predictive of better mental health and positive functioning, including lower levels of depression, anxiety, and obsessivecompulsiveness, and higher levels of global self-esteem, identity integration, moral selfapproval, and meaning in life. Intrinsic religiousness was not predictive of shame, perfectionism, and eating disorder symptoms. These findings are consistent with many prior studies that have found religiousness and spirituality to be positively associated with better mental health and positive psychosocial functioning in adolescents and young adults.
\end{abstract}

Keywords Intrinsic religiousness $\cdot$ Spirituality $\cdot$ Adolescent mental health $\cdot$ Latter-day saint mental health

\section{Introduction}

Since the beginnings of modern psychology, the relationship between religion and mental health has been a topic of controversy (Wulff 1997). Early empirical findings were ambiguous and did little to resolve the controversy (Bergin 1983; Strommen 1971). However, these studies did help make several things clear. First, both religion and mental health are

Peter W. Sanders

peter_sanders@byu.edu

P. Scott Richards

scott_richards@byu.edu

1 Brigham Young University, 340 MCKB, Provo, UT 84602, USA 
complex, multidimensional phenomena-some types of religiousness may be positively associated with some types of mental health, but not others. Second, the empirical relationships observed between religion and psychological functioning depend on how researchers define and measure these constructs (Batson and Ventis 1982; Bergin 1983).

During the past few decades, as hundreds of studies have been done, some clarity in this domain has begun to emerge. The most consistent, frequently repeated finding is that religious devoutness in adolescents and adults tends to be positively associated with positive psychological functioning (e.g., greater subjective well-being, life satisfaction, self-esteem and coping, and less anxiety and depression), social conduct (e.g., greater marital satisfaction and lower rates of divorce, substance abuse, premarital and extramarital sex, teenage pregnancy, crime and delinquency, and suicide), and physical health (e.g., lower rates of illnesses such as cancer, coronary heart disease, hypertension, and cirrhosis of the liver; more ability to cope with and recover from illness; and greater longevity) (Allen and Wang 2014; Barton et al. 2013; Desrosiers and Miller 2007; Donahue 1985; Koenig et al. 2001; Payne et al. 1991; Miller et al. 1997, 2000; Miller and Thoresen 2003).

Despite the accumulating evidence that various measures of religious devoutness and spirituality are associated with better mental health and psychosocial functioning, Richards and Bergin (2014) concluded that the "lack of behavioral science research about members of specific religious and spiritual traditions remains a deficiency in the field" (p. 486). Research that investigates the mental health issues and needs of members of specific religious denominations would be valuable because it could give insights into what issues and strategies may be most important for mental health prevention and treatment with specific faith traditions (Richards and Bergin 2014).

During the past two decades, researchers at Brigham Young University have published numerous studies of members of the Church of Jesus Christ of Latter-day Saints (LDS) using a variety of measures of religiousness, spirituality, mental health, and psychosocial functioning (e.g., Allen and Heppner 2011; Allen and Wang 2014; Allen et al., in press; Bartz et al. 2010; Bergin et al. 1987; Bergin et al. 1988; Edgington et al. 2008; Richards 1994; Richards and Davison 1992; Richards et al. 1989, 1993). This research has documented the positive role that religion and spirituality play in the lives of many Latter-day Saints, but it has also provided insights into what psychosocial issues psychotherapists may need to address with Latter-day Saints clients (Ulrich et al. 2014). In the present article, we report the findings of three additional studies conducted with Latter-day Saint youth (late adolescents and young adults). These three studies give additional insight into the relationships between religion, spirituality, and mental health in the lives of Latter-day Saint adolescents and young adults.

\section{Study 1}

Hundreds of studies conducted during that past few decades have shown that intrinsic religiousness is associated with better psychological functioning (Koenig et al. 2001; Miller and Thoresen 2003). In Study 1, we undertook to empirically examine the relationship of intrinsic religiousness with several measures of psychosocial functioning, including depression, anxiety, shame, and perfectionism, in young Latter-day Saint college students. We also investigated whether intrinsic religiousness would predict better psychological functioning in the presence of Christian orthodoxy and religious fundamentalism. More data about the relations between intrinsic religiousness, Christian orthodoxy, and fundamentalism will help further clarify understandings of these three ways of being religious. 


\section{Method}

\section{Participants}

The sample consisted of 247 students at Brigham Young University: 144 [58.3\%] were males and 103 [41.7\%] were females. The ages of the subjects ranged from 17 to 26 years, with a modal age of 18 years and a mean age of 20.5 years: $53(21.5 \%)$ participants were 18 years old; $50(20.2 \%)$ were 19 years; $25(10.1 \%)$ were 20 years; $35(14.2 \%)$ were 21 years; 29 $(11.7 \% \%)$ were 22 years; $27(10.9 \%)$ were 23 years; 18 (7.3\%) were 24 years; and 7 $(2.8 \%)$ were 25 years. One hundred $(40.5 \%)$ of the subjects were freshman, $57(23.1 \%)$ were sophomores, $61(24.7 \%)$ were juniors, and $29(11.7 \%)$ were seniors. Two hundred and eighteen $(88.3 \%)$ of the subjects were single, $28(11.3 \%)$ were married, and one $(0.4 \%)$ was divorced. Ninety-eight percentage of the subjects were Latter-day Saints, with one Lutheran and one Catholic.

\section{Procedures}

One hundred and twenty-eight participants were recruited by mail, and another 119 participants were recruited from general psychology classes at BYU. Participants who completed the measures received two tickets to a local movie theater as compensation for their participation. American Psychological Association (APA 1994) guidelines were followed in the recruitment of participants. All participants completed a packet that consisted of an informed consent document, a demographic questionnaire, and the various religious and psychological measures.

\section{Instruments}

The Religious Orientation Scale (ROS; Allport and Ross 1967) is a 20-item measure designed to measure religious orientation: extrinsic or intrinsic. This measure was used to determine the levels of intrinsic religiousness in the sample. The ROS has demonstrated internal consistency reliability coefficients ranging from .79 to .86 (Brewczynski and MacDonald 2006; Genia 1993). Validity studies have shown a relationship between the ROS and measures of religious beliefs and religious orthodoxy, yielding a validity coefficient of .76 (Donahue 1985).

The Christian Orthodoxy Scale (COS; Fullerton and Hunsberger 1982) is a 24-item scale, examining the level of "acceptance of well-defined, central tenets of the Christian religion" (Fullerton and Hunsberger 1982, p. 318). The reliability for the COS has shown internal consistencies from .63 to .98 (Fullerton and Hunsberger 1982). Validity studies have correlated the COS with measures designed to assess belief in God, belief in Jesus, and frequency of religious activities.

The Religious Fundamentalism Scale (RFS; Altemeyer and Hunsberger 1992) is a 20-item measure designed to measure religious fundamentalism. Reliabilities for the RFS have been reported as high as .93 to .95 (internal consistency). Validity studies have shown the measure to correlate highly with authoritarianism ( $r=.66$ to .75$)$.

The State-Trait Anxiety Inventory (STAI; Spielberger et al. 1983) is a 40-item measure designed to measure both temporary, state anxiety, and more enduring, trait anxiety. Because the focus of this study was on the more abiding personality factor of anxiety, only the trait items were used. 
The Beck Depression Inventory (BDI; Beck 1976) is a 4-point Likert scale used to measure depression in which it asks the participant to report his or her feelings and behavioral patterns. The BDI has reported high coefficients of internal consistency, ranging from .73 to .95 . Test-retest reliability has been reported from .48 to .90 . Construct validity studies have provided support for the validity of the BDI (e.g., Berdnt 1990).

The Burns Perfectionism Scale (BPS; Burns 1980) is a 10-item instrument that examines perfectionism through thinking errors. Reliability studies on the BPS have shown an internal consistency score of .76 (Broday 1988). Validity studies have yielded validity coefficients from .40 to .77 with the Multidimensional Perfectionism Scale (Hewitt et al. 1991).

The Test of Self-Conscious Affect (TOSCA; Tangney et al. 1989) is an instrument designed to measure pride, externalization, shame, and guilt. Reliability studies regarding the TOSCA have yielded test-retest correlation coefficients ranging from .73 to .80 (Tangney et al. 1989). Evidence supporting the validity of the TOSCA has been published (e.g., Tangney et al. 1995).

\section{Results}

Descriptive statistics of the participants' scores on the various dependent measures indicated that this sample of LDS individuals was intrinsically religious $(M=37.0$, $\mathrm{SD}=4.4)$, highly orthodox $(M=159.9, \mathrm{SD}=6.5)$, and above average in fundamentalism $(M=130.1, \mathrm{SD}=17.4)$ when compared to other samples of college students and adults (Altemeyer and Hunsberger 1992; Donahue 1985; Fullerton and Hunsberger 1982). In regard to their psychological adjustment, the participants were slightly below average in anxiety $(M=36.2 ; \quad \mathrm{SD}=8.1), \quad$ depression $(M=5.8 ; \quad \mathrm{SD}=5.6), \quad$ perfectionism $(M=21.4 ; \mathrm{SD}=6.2)$, and shame $(M=40.9 ; \mathrm{SD}=8.2)$ when compared to other samples of college students and adults (Beck 1976; Burns 1980; Rokeach 1960; Spielberger et al. 1983; Tangney et al. 1989). Zero-order correlations (see Table 1) show that all three ways of being religious (e.g., intrinsically religious, orthodoxy, and fundamentalism) were negatively correlated with depression and anxiety, but none of them were correlated with shame or perfectionism.

We performed stepwise multiple regression analyses with intrinsically religious, orthodoxy, and fundamentalism as predictors and depression, anxiety, shame, and

Table 1 Study 1: Intercorrelations of variables

\begin{tabular}{|c|c|c|c|c|c|}
\hline & 1 & 2 & 3 & $M$ & $\mathrm{SD}$ \\
\hline 1. Intrinsic religiousness & - & & & 16.9 & 4.4 \\
\hline 2. Religious orthodoxy & $-.34 * *$ & - & & 64.0 & 11.8 \\
\hline 3. Religious fundamentalism & $-.51 * *$ & $.44 * *$ & - & 30.1 & 17.4 \\
\hline 4. Depression & $-.34 * * *$ & $-.24 * * *$ & $-.32 * * *$ & 5.8 & 5.6 \\
\hline 5. Anxiety & $-.41 * * *$ & $-.24 * * *$ & $-.27 * * *$ & 36.2 & 8.1 \\
\hline 6. Shame & -.07 & -.03 & .04 & 40.9 & 8.2 \\
\hline 7. Perfectionism & -.03 & .01 & .09 & 21.4 & 6.2 \\
\hline
\end{tabular}

$N=247 . * p<.05 ; * * p<.01 ; * * * p<.001$, two-tailed 
Table 2 Study 1: Religious predictors of mental health outcome variables

\begin{tabular}{lllll}
\hline & $R^{2}$ & Predictor & $\beta$ & Zero-order $r$ \\
\hline Depression & .117 & IR & -.243 & -.342 \\
& .145 & RF & -.194 & -.318 \\
Anxiety & .167 & IR & -.409 & -.409 \\
\hline
\end{tabular}

$I R$ intrinsically religious, $R F$ religious fundamentalism

perfectionism as outcome variables (see Table 2). Intrinsic religiosity and fundamentalism were found to predict lower levels of depression (intri: $R^{2}=.117, F(1,245)=32.42$, $p<.01$ ); fund: $\left.R^{2}=.14, F(1,244)=20.64, p<.05\right)$. There was no statistically significant relationship between Christian orthodoxy and depression. Intrinsic religiosity was found to predict decreased anxiety $\left(R^{2}=.17, F(1,244)=49.11, p<.001\right)$. Fundamentalism and orthodoxy did not predict decreased anxiety. None of the independent variables predicted lower levels of shame or increased unhealthy perfectionism.

\section{Discussion}

The finding that intrinsic religiousness was found to predict lower levels of depression and anxiety in our late adolescent and young adult Latter-day Saint sample is consistent with previous research that has found that intrinsic religiosity tends to be associated with less depression (Allen and Heppner 2011; Allen and Wang 2014; Batson et al. 1993; Gartner et al. 1991; Payne et al. 1991). The finding that intrinsically religious people tend to be less anxious has also been observed in other studies (e.g., Allen and Heppner 2011; Batson et al. 1993; Bergin et al. 1987).

The finding that intrinsic religiousness is not associated with higher levels of shame is also consistent with previous research (e.g., Allen et al. 2015; Richards 1991). In light of speculations that religiously devout people may be more susceptible to unhealthy perfectionistic strivings (e.g., Heise and Steitz 1991; Mebane and Ridley 1988; Richards et al. 1993), the nonsignificant relationship between intrinsicness and perfectionism is of particular interest. Recently, there has been research examining two dimensions of perfectionism: adaptive (healthy) and maladaptive (unhealthy) perfectionism (Allen and Wang 2014; Allen et al., in press) in which adaptive is associated with positive mental health, while maladaptive is correlated with increased depression and anxiety (Allen and Wang 2014). Additional research is needed to assess the benefits of adaptive perfectionism and the unhealthy effects of maladaptive perfectionism among Latter-day Saints and members of other religious denominations.

Our finding that religious fundamentalism was a significant predictor of lower levels of depression and not a significant predictor of anxiety, shame, and perfectionism is also of interest and adds to the scant database on religious fundamentalism and psychological adjustment. Although a fundamentalist religious orientation has often been negatively portrayed in psychological literature (Glock and Stark 1966; McFarland 1989), our study indicates that a fundamentalist religious orientation is by no means uniformly unhealthy as evidenced by its negative association with depression. Thurstone (1998) pointed out that although fundamentalist Christian churches may have some unhealthy aspects to them, they also provide much in the way of structure and social support. She posited that the majority of members of fundamentalist churches have good psychological functioning. 


\section{Study 2}

In addition to examining the relationship of various religious variables to mental health concerns, it is important to examine the ways that religion and spirituality may contribute to positive psychosocial functioning. One area that has received some attention in the literature is the relationship between self-esteem and religiosity. Research investigating the relationship between religiosity and self-esteem has yielded mixed findings. For example, Gartner et al. (1991) reviewed eighteen published studies and dissertations and concluded that "four found the religiously committed to be lower in self-esteem, eight found no differences between groups, and six found the religiously committed to be higher in self-esteem" (p. 12). Other researchers have also observed inconsistent relations between religiousness and self-esteem (e.g., Batson et al. 1993; Gartner 1983; Gartner et al. 1991).

Some researchers have surmised that one explanation for these mixed findings is that studies have used non-specific religious and self-esteem measures (Watson et al. 1985). To gain a better understanding of the relations between religiosity and self-esteem, researchers need to investigate what types of religiousness might be associated with what components of self-esteem. Therefore, the purpose of this study is to examine which dimensions of religiosity, as measured by the Religious Status Inventory (RSI), predict specific aspects of self-esteem, as measured by the Multidimensional Self-Esteem Inventory (MSEI).

\section{Methods}

\section{Setting and Population}

This study was conducted at Brigham Young University. BYU is a private, religious institution sponsored by The Church of Jesus Christ of Latter-day Saints (LDS). Although we have noted some restrictions in range on measures of religious and spirituality in our BYU samples, the variability in scores has been sufficient for detecting significant relationships between religious devoutness and other psychosocial variables.

\section{Participants}

The participants were 310 students recruited from teacher education, religion, and psychology classes. One hundred and eighty-seven females (60.3\%) participated compared to 123 males $(39.7 \%)$. The ages of the participants ranged from 16 to 46, with a modal age of 21 and a mean age of 22.3. The frequency and percentage of the sample at each age are as follows (ages with $n<5$ were not listed): 18 ( $n=17,5.5 \%), 19(n=30,9.7 \%), 20$ $(n=46,14.8 \%), 21(n=59,19.0 \%), 22(n=46,14.8 \%), 23(n=38,12.3 \%), 24$ $(n=30,9.7 \%), 25(n=10,3.2 \%)$, and $26(n=11,3.5 \%)$. Two hundred and nine (67.4\%) participants were single, 98 (31.6\%) married, and $3(1.0 \%)$ divorced. Caucasian was the dominant ethnic background ( $n=275,88.7 \%)$, followed by Asian $(n=8,2.6 \%)$ and Hispanic ( $n=8,2.6 \%$ ). Other groups had less than five representatives in the sample. Three hundred and eight $(99.4 \%)$ of the participants were LDS, and two participants (.6\%) had no religious preference. 


\section{Measures}

\section{Religious Status Inventory}

The Religious Status Inventory (RSI) is a 160-item inventory measuring eight dimensions of Christian religiosity: (1) awareness of God; (2) acceptance of God's grace and steadfast love; (3) knowing God's leadership and direction; (4) being ethical; (5) being repentant and responsible; (6) involvement in organized religion; (7) experiencing fellowship; and (8) affirming openness in faith (Maloney 1994, 1988). The RSI was chosen for this study as it represented a multidimensional assessment of a theoretically healthy, internalized way of being religious.

\section{Multidimensional Self-Esteem Inventory}

The Multidimensional Self-Esteem Inventory (MSEI) is a 116-item objective, self-report inventory measuring nine components of self-esteem (competence, lovability, likeability, personal power, self-control, moral self-approval, body appearance, identity integration, and body functioning) as well as global self-esteem (Epstein 1980; Epstein and O'Brien 1983). The MSEI was selected because it measures multiple dimensions of self-esteem.

\section{Procedures}

Each participant was handed a packet that included an informed consent letter, a form for demographic data, and the two inventories. Participants did not provide their names but were given a number in order to maintain anonymity and ensure confidentiality. Total participation time for students was approximately $50 \mathrm{~min}$. Participants received extra credit in their respective classes and movie passes for their participation.

\section{Data Analysis}

Descriptive statistics including means, standard deviations, and ranges were calculated to describe subjects' scores on the RSI and MSEI. Stepwise multiple regression analyses were used to determine which spiritual maturity variables were most predictive of both specific dimensions of self-esteem and global self-esteem. The criterion variables were each of the scales of the MSEI, with all RSI scales being used as predictors. With the usage of stepwise multiple regression, RSI variables that did not significantly predict the aspect of selfesteem in the model were excluded.

\section{Results}

The mean score from this sample on the RSI was 634.54 with a standard deviation of 44.61 and a range of 273. This indicates that the BYU student total was higher than those of the normative sample of the RSI. The participants obtained an overall mean score of 415.84 on the Multidimensional Self-Esteem Inventory (MSEI) with a standard deviation of 51.38 and a range of 252. The current sample's mean values for all subscales were as high as or higher than the MSEI normative sample of 785 college students. 
The four self-esteem variables that were best predicted by the RSI subscales were as follows: Moral Self-Approval $\left(R^{2}=.291\right)$, Lovability (.239), Global Self-Esteem (.233), and Identity Integration (.215). Table 3 shows the RSI predictors that were used in each model and their beta weights. These results suggest that some RSI variables had relatively strong predictive power in explaining the variance of various self-esteem scales (with the models explaining between $1 / 5$ and $1 / 3$ of the MSEI subscale variance), suggesting that greater religiosity was generally predictive of greater self-esteem.

Two religious variables were negatively predictive of self-esteem in the presence of the other predictors (though not in their zero-order correlations), which suggests that there may be moderating relationships between some of the variables. Additionally, although some RSI variables were predictive of several MSEI subscales (i.e., acceptance of love and grace, involvement in organized religion), some predictors were only significant in relation to specific MSEI subscales. This lends support for the hypothesis that the relationship between religiosity and self-esteem should be examined using multidimensional measures.

Table 3 Study 2: RSI predictors of self-esteem variables
AGGL Acceptance of God's grace and love, IOR involvement in organized religion, $A G$ awareness of God, $B R$ being repentant, $A O F$ affirming openness in faith, $E F$ experiencing fellowship, KGLD knowing God's leadership and direction

\begin{tabular}{|c|c|c|c|c|}
\hline Self-esteem variable & $R^{2}$ & Predictor & $\beta$ & Zero-order $r$ \\
\hline \multirow[t]{3}{*}{ Moral Self-Approval } & \multirow[t]{3}{*}{.291} & AGGL & .241 & .478 \\
\hline & & IOR & .211 & .470 \\
\hline & & $\mathrm{AG}$ & .173 & .446 \\
\hline \multirow[t]{5}{*}{ Lovability } & \multirow[t]{5}{*}{.239} & IOR & .265 & .413 \\
\hline & & AGGL & .124 & .399 \\
\hline & & BR & .139 & .293 \\
\hline & & $\mathrm{AOF}$ & -.174 & .208 \\
\hline & & KGLD & .186 & .407 \\
\hline \multirow[t]{5}{*}{ Global Self-Esteem } & \multirow[t]{5}{*}{.233} & AOGL & .270 & .407 \\
\hline & & $\mathrm{BR}$ & .214 & .321 \\
\hline & & IOR & .270 & .362 \\
\hline & & $\mathrm{AOF}$ & -.157 & .171 \\
\hline & & $\mathrm{EF}$ & -.132 & .121 \\
\hline \multirow[t]{2}{*}{ Identity Integration } & \multirow[t]{2}{*}{.215} & IOR & .318 & .439 \\
\hline & & AGGL & .191 & .393 \\
\hline \multirow[t]{2}{*}{ Personal power } & \multirow[t]{2}{*}{.200} & $\mathrm{BR}$ & .311 & .397 \\
\hline & & KGLD & .222 & .343 \\
\hline \multirow[t]{2}{*}{ Competence } & \multirow[t]{2}{*}{.185} & $\mathrm{BR}$ & .300 & .378 \\
\hline & & IOR & .220 & .326 \\
\hline \multirow[t]{2}{*}{ Likability } & \multirow[t]{2}{*}{.183} & AGGL & .354 & .411 \\
\hline & & $\mathrm{EF}$ & .134 & .286 \\
\hline \multirow[t]{2}{*}{ Self-control } & \multirow[t]{2}{*}{.152} & AGGL & .310 & .371 \\
\hline & & $\mathrm{BR}$ & .135 & .275 \\
\hline \multirow[t]{3}{*}{ Body appearance } & \multirow[t]{3}{*}{.088} & AGGL & .214 & .230 \\
\hline & & $\mathrm{BR}$ & .187 & .227 \\
\hline & & $\mathrm{AOF}$ & -.144 & .031 \\
\hline Body functioning & .073 & BR & .269 & .269 \\
\hline
\end{tabular}




\section{Discussion}

Previous research on religiousness and self-esteem has yielded mixed findings: some positive, some negative, and some nonsignificant relationships (Gartner et al. 1991). The findings in the present study are reflective of this trend in that they showed that certain aspects of religiosity were associated with some types of self-esteem but not others. The stepwise multiple regressions found the following self-esteem variables to be most associated with spiritual maturity: Moral Self-Approval, Lovability, Global Self-Esteem, and Identity Integration. These results suggest that religious participants were likely to feel that they were loved, to have a clear sense of who they are, and to feel that their lives are in congruence with their values.

Some spiritual predictors were very robust, while others did not predict any aspect of self-esteem in the presence of the other variables. Acceptance of God's grace and love, involvement in organized religion, and being repentant and responsible were the most robust positive predictors of many types of self-esteem. This finding suggests that it may be advisable for future studies to use these variables in their studies. The finding that involvement in organized religion was a highly positive predictor of various aspects of selfesteem was especially interesting, given that non-religious spirituality has often been seen as the more positive predictor of functioning. Even in the presence of several predictors, being involved in organized religion appears to be beneficial for the adolescents and young adults in this Latter-day Saint sample.

Despite most of the RSI variables being predictive of greater self-esteem, the RSI variables of (1) affirming openness of faith and (2) experiencing fellowship were both predictive of less global self-esteem, even though the zero-order correlations for each of these variables were positively associated with global self-esteem. Thus, it is possible that these variables are moderated by one of the other predictors in the regression.

It was also of interest that the RSI variables demonstrated little predictive value for dimensions of self-esteem related to participants' views of their physical attractiveness or energy levels/athleticism. This finding is not entirely unexpected, given that many religions do not put extensive focus on valuing physical attractiveness or athleticism. Overall, the spiritual maturity variables were predictive of substantial amounts of the variance of most dimensions of self-esteem, with the vast majority of the associations being positive.

\section{Study 3}

Both theory and research suggest that materialistic values lie in opposition to values espoused in many religious and spiritual traditions (Richards and Bergin 2005). For instance, valuing social status, sensual gratification, and personal success have been shown to conflict with values such as compassion and appreciation of nature (Burroughs and Rindfleisch 2002). Being on a spiritual journey can shift one's perspective from one of selfabsorption and over-acquisition of material goods to a focus on altruism, community mindedness, and connection with the larger universe.

There is evidence that religious involvement and connection with God can provide a stable identity and a sense of purpose in life in adolescents and young adults which can be protective factors against the development of psychological problems in adolescents and young adults (e.g., Barton et al. 2013; Miller et al. 1997, 2000). Having a spiritual life that feels purposeful has been shown to be associated with pro-social behavior, moral 
commitment, and high self-esteem (Benson et al. 2012). Having a life that lacks purpose has been correlated with depression, self-absorption, addictions, a lack of productivity, and an inability to sustain stable interpersonal relations (Steger et al. 2006).

In Study 3, we investigated whether intrinsic and extrinsic religiousness and selftranscendence are predictive of lower levels of psychological distress (i.e., depression, anxiety, obsessive-compulsiveness, global distress, and eating disorder symptoms). We also investigated whether these same religious-spiritual measures are predictive of higher levels of life meaning and purpose.

\section{Description of Subjects}

The participants were 341 students from Brigham Young University. The sample was composed of $213(62.5 \%)$ female and 128 male $(37.5 \%)$ participants. The ages of the participants ranged from 17 to 41 , with a modal age of 19 and a mean age of 19.8. The frequency and percentage of the sample at each age are as follows (ages with $n<5$ are not listed): 18 years $(n=100,29.3 \%), 19$ years $(n=125,36.7 \%), 20$ years $(n=33$, $9.7 \%), 21$ years $(n=29,8.5 \%), 22$ years $(n=15,4.4 \%), 23$ years $(n=13,3.8 \%)$, 24 years $(n=11,3.2 \%)$, 25 years $(n=6,1.8 \%)$. Three hundred and fourteen participants $(92.6 \%)$ were single and $25(7.4 \%)$ were married. The sample was primarily Caucasian $(n=321,94.4 \%)$, with a small number of Asian $(n=8,2.4 \%)$, Hispanic $(n=5,1.5 \%)$, Pacific Islander $(n=2, .6 \%)$, African American $(n=1, .3 \%)$, and Native American $(n=1, .3 \%)$ participants. Three hundred and thirty-nine $(99.4 \%)$ participants were LDS, one (.3\%) participant was Buddhist, and one (.3\%) participant indicated "other."

\section{Procedures and Methods}

Participants were recruited from classes in the religion department at Brigham Young University. When participants arrived at the testing room, a research assistant who had been trained in the data collection procedures informed them about the purpose of the study and asked them to read the consent document. When participants completed the packet of measures, the research assistant collected their questionnaire and placed it in an envelope and sealed it. Participants were given a $\$ 10$ gift certificate. APA guidelines were followed in protecting the confidentiality and anonymity of the participants' test results.

\section{Measures}

The Religious Orientation Scale (ROS) is a 20-item scale that measures the constructs of intrinsic and extrinsic religiosity (Allport and Ross 1967). It was described in more detail in Study 1.

The Self-Transcendence Questionnaire (STS) is a 15-item scale that measures the concept of self-transcendence (Reed 1991). Self-transcendence is considered an indicator of healthy development, is characterized by both inward introspection and outward concern for others, and involves an expansion of personal boundaries leading to a stabilized and broadened worldview (Maslow 1971; Wilber 2000). Frankl (1966) believed that selftranscendence is central to the ability of humans to create meaning. Abraham Maslow 
suggested transcendence is "the very highest and most inclusive or holistic levels of human consciousness, behaving and relating, as ends rather than means, to oneself, to significant others, to human beings in general, to other species, to nature, and to the cosmos" (1971, p. 269).

The Eating Attitudes Test (EAT) is a widely used measure of disordered eating and the characteristics of eating disorders (Garner and Garfinkel 1979). The abbreviated EAT-26 was used in this study and consists of 26 items. The EAT has demonstrated high reliability and consistency and is considered an effective screening tool in both clinical and nonclinical populations (Garfinkel and Garner 1982; Garner and Garfinkel 1979).

The Meaning in Life Questionnaire (MILQ) is a 10-item scale designed to measure meaning in life (Steger et al. 2006). The scale is comprised of two 5-item subscales. The MILQ Presence (MILQ-P) subscale measures the presence of meaning in life and includes items such as "I understand my life's meaning." The MILQ Search (MILQ-S) subscale measures the extent to which one is searching for meaning in life and includes items such as "I am always searching for something that makes my life feel significant." The MILQ is scored on a 7 point Likert-type scale with responses ranging from absolutely untrue (1) to absolutely true (7). The MILQ has demonstrated good validity and reliability. Cronbach's alpha for the MILQ-P and MILQ-S was .86 and .92, respectively.

The Schedule for Meaning in Life Evaluation (SMILE) is a respondent-generated measure of individual meaning in life (Fegg et al. 2008). It asks participants (1) to name three to seven domains that they judge to be important to their individual meaning in life; (2) to rate their current level of satisfaction in each of these domains using a seven-point Likert scale (range -3 to +3 ); and (3) to rate the importance of each of their chosen areas using an eight-point adjectival scale (range 0-7).

The Brief Symptom Inventory (BSI) is one of the most widely used measures of overall psychological distress (Derogatis and Melisaratos 1983). The 53-item BSI was used in this study. This measure has subscales that measure depression, anxiety, and obsessive-compulsiveness. The total scale yields the Global Severity Index (GSI), an overall gauge of psychological distress.

\section{Results}

Means and standard deviations for the participants on each measure used in this study were calculated for comparative purposes. The mean score for the MILQ Presence scale and MILQ Search scales was $30.34(\mathrm{SD}=3.9)$ and $22.44(\mathrm{SD}=7.62)$, respectively. This was higher than the university sample used in the validation study of the MILQ (Steger et al. 2006). The mean for the SMILE was 30.9 (SD = 17.8). The means and standard deviations for the BSI scales are as follows: Anxiety $(M=0.72, \mathrm{SD}=.55)$, Depression $(M=0.79$, $\mathrm{SD}=.70), \quad$ Obsession-Compulsion $\quad(M=1.20, \quad \mathrm{SD}=.74), \quad$ and Global Severity $(M=0.71, \mathrm{SD}=.49)$. These means are slightly lower than those reported by Cochran and Hale (1985) for college students at a private university. The means and standard deviations for the ROS extrinsic and intrinsic scales were $30.87(\mathrm{SD}=5.3)$ and $37.4(\mathrm{SD}=4.4)$, respectively, which indicates that this sample is highly intrinsic in their religious orientation (Donahue 1985). The STS had a mean of $50.62(\mathrm{SD}=5.15)$. This mean is slightly higher or comparable to those reported in previous research (e.g., $M=43.8, \mathrm{SD}=8.7$; Ramer et al. 2006; $M=50.0, \mathrm{SD}=5.5$; Matthews and Cook 2009). The EAT for both 
men and women had a mean of $6.7(\mathrm{SD}=7.9)$, but the mean for women only was 8.0 $(\mathrm{SD}=8.8)$.

Pearson's correlations between the religious-spiritual variables and the mental health and meaning in life variables were calculated and are presented in Table 3. The bivariate correlations reveal that both intrinsic religiousness and self-transcendence were significantly and positively correlated with meaning in life, negatively correlated with depression, anxiety, obsessive-compulsiveness, and global symptom severity, but uncorrelated with eating disorder symptoms and the MILQ Search variable. The selftranscendence scale showed stronger associations with all of the mental health and meaning in life variables compared to intrinsic religiousness. The extrinsic religiousness scale was associated with more psychiatric disturbance and less meaning in life.

A stepwise multiple regression was performed to determine which of the three religious-spiritual variables (self-transcendence, intrinsic religiosity, and extrinsic religiosity) were most strongly predictive of the various mental health and meaning in life variables. The results of these regressions are shown in Table 4. These analyses indicate that the religious-spiritual variables are strongly predictive of the presence of meaning in one's life (MILQ Presence and SMILE) and moderately to strongly predictive of the mental health variables measured by the Brief Symptom Inventory. Intrinsic religiousness predicted higher levels of meaning in life (MILQ Presence and SMILE). Intrinsic religiousness was not significantly predictive of any of the mental health variables in the presence of selftranscendence and extrinsic religiousness. Extrinsic religiosity was predictive of less meaning in life and of more symptoms of anxiety, obsessive-compulsiveness, and depression (Table 5).

Self-transcendence was the strongest predictor of all of the mental health and meaning in life variables except for eating disorder attitudes, of which gender was the strongest predictor. The results suggest that greater self-transcendence is associated with greater meaning in life and less depression, even in the presence of the other spiritual variables and

Table 4 Study 3: Intercorrelations of variables

\begin{tabular}{|c|c|c|c|c|c|}
\hline & 1 & 2 & 3 & $M$ & $\mathrm{SD}$ \\
\hline 1. Intrinsic religiousness & - & & & 37.4 & 4.4 \\
\hline 2. Extrinsic religiousness & $-.27 * * *$ & - & & 30.9 & 5.3 \\
\hline 3. Self-transcendence & $.32 * *$ & -.10 & - & 50.6 & 5.1 \\
\hline 4. MILQ Presence & $.53 * * *$ & $-.25 * * *$ & $.52 * * *$ & 30.3 & 3.9 \\
\hline 5. MILQ Search & -.08 & $.20 * * *$ & $-.21 * * *$ & 22.4 & 7.6 \\
\hline 6. SMILE & .35 & -.04 & $.62 * * *$ & 30.9 & 17.8 \\
\hline 7. BSI global severity & $-.22 * * *$ & $.23 * * *$ & $-.51 * * *$ & .71 & .49 \\
\hline 8. BSI anxiety & $-.19 * * *$ & $.17 * * *$ & $-.34 * * *$ & .72 & .55 \\
\hline 9. BSI depression & $-.26^{* * *}$ & $.18 * * *$ & $-.57 * * *$ & .79 & .70 \\
\hline 10. BSI obsessive compulsion & $-.13 *$ & $.14^{* *}$ & $-.42 * * *$ & 1.2 & .74 \\
\hline 11. EAT (total sample) & -.01 & .10 & $-.17 * *$ & 6.7 & 7.9 \\
\hline 12. EAT (female only) & -.09 & .14 & -.28 & 8.0 & 8.8 \\
\hline
\end{tabular}

$N=341 . * p<.05 ; * * p<.01 ; * * * p<.001$, two-tailed. MILQ Meaning in Life Questionnaire, SMILE The Schedule for Meaning in Life Evaluation, EAT Eating Attitudes Test, BSI Brief Symptom Inventory, Trans Self-Transcendence, Intrin intrisic religiosity, Extrin extrinsic religiosity 
Table 5 Study 3: Spiritual predictors of mental health and meaning in life

$M I L Q$ Meaning in Life

Questionnaire, SMILE The

Schedule for Meaning in Life

Evaluation, EAT Eating Attitudes

Test, BSI Brief Symptom

Inventory, Trans self-

transcendence, Intrin intrisic

religiosity, Extrin extrinsic

religiosity, Gend gender

\begin{tabular}{lclrc}
\hline Outcome variable & $R^{2}$ & Predictor & $\beta$ & Zero-order $r$ \\
\hline MILQ presence & .428 & Trans & .416 & .538 \\
& & Intrin & .349 & .514 \\
SMILE total & & Extrin & -.116 & -.225 \\
& .410 & Trans & .270 & .407 \\
BSI depression & & Intrin & .214 & .321 \\
& .386 & Trans & -.597 & -.589 \\
& & Gend & .174 & .093 \\
BSI global & & Extrin & .135 & .184 \\
& .338 & Trans & -.522 & -.516 \\
& & Gend & .202 & .130 \\
BSI anxiety & & Extrin & .188 & .228 \\
& .211 & Trans & -.368 & -.350 \\
& & Gend & .270 & .218 \\
BSI obsessive compulsive & .201 & Trans & -.447 & -.434 \\
& & Gend & .115 & .063 \\
EAT total & .089 & Gend & .248 & .225 \\
& & Trans & -.199 & -.170 \\
MILQ search & .076 & Trans & -.195 & -.212 \\
& & Extrin & .176 & .195 \\
\hline & & & & \\
\hline & & & & \\
& & & &
\end{tabular}

gender. Gender was a significant predictor of most mental health outcomes, but not of meaning in life. Males scored lower on depression, anxiety, obsessive-compulsiveness, global symptom severity, and eating disorder symptoms compared to females.

\section{Discussion}

The findings of Study 3 are consistent with other studies that have shown that intrinsic religiousness, connections with a religious community, and faith in God or a higher power are positively associated with mental health and positive psychosocial functioning in adolescence and young adulthood (e.g., Benson et al. 2012; Miller et al. 1997, 2000; Richards 1991). Our findings provide evidence that intrinsic religiousness was more strongly predictive of life meaning and purpose than it was of less depression, anxiety, obsessive-compulsiveness, and global symptom severity.

The finding that self-transcendence was strongly predictive of both meaning in life and fewer psychiatric symptoms seems consistent with Miller and her colleagues' finding that an inner awareness and sense of relationship with a higher power is more strongly related to mental health and thriving in adolescents and young adults than is institutional involvement, especially when that involvement is not fully chosen or internalized (Miller 2015; Barton et al. 2013; Desrosiers and Miller 2007; Miller et al. 1997, 2000).

The finding that self-transcendence was associated with fewer eating disorder symptoms-more strongly than was intrinsic religiousness-was a noteworthy finding that seems consistent with eating disorders specialists who have observed that personal spirituality is an important resource in recovery for eating disorder patients (Berrett et al. 
2010). The finding that extrinsic religiousness was predictive of and positively associated with more depression, anxiety, and global symptom severity seems consistent with Miller's (2015) conclusion that adherence to or involvement in a religion or creed for utilitarian reasons without a sense of personal ownership or relationship with the sacred is not associated with better functioning in adolescents.

\section{General Discussion}

There are some limitations of the three studies reported in this article that need to be kept in mind. First, they were all correlational studies and thus conclusions about causal relationships are not warranted. Second, the denominational homogeneity of the sample used in the studies limits the generalizability of the results and possibly the magnitude of some of the observed relationships.

Despite these limitations, the studies had a number of strengths. First, the sample sizes for each study were relatively large, and collectively, 898 students participated. Second, across the three studies, multiple measures of religiousness, spirituality, mental health, and positive psychosocial functioning were used. Third, because of the large sample sizes, it was possible to use multiple regression analysis to explore the relative strength of the relationships between the religious and spiritual measures and various dimensions of mental health and positive functioning. The measurement of multiple types of religiousness and a variety of mental health indicators with three separate samples of college students adds to the robustness our findings.

The studies reported here add to the growing empirical evidence that intrinsic religiousness and spirituality are "vast untapped resource[s] in our understanding of human development, illness, health, and healing" (Miller 2015, p. 28). They also provide additional insight into the religious, spiritual, and psychological strengths and possible struggles that Latter-day Saint adolescents and young adults experience.

\section{References}

Allen, G. E. K., \& Heppner, P. P. (2011). Religiosity, coping, and psychological well-being among LatterDay Saint Polynesians in the US. Asian American Journal of Psychology, 2(1), 13.

Allen, G. E. K., \& Wang, K. T. (2014). Examining religious commitment, perfectionism, scrupulosity, and well-being among LDS individuals. Psychology of Religion and Spirituality, 6(3), 257-264.

Allen, G. E. K., Wang, K. T., \& Stokes, H. (2015). Examining legalism, scrupulosity, family perfectionism, and psychological adjustment among LDS individuals. Mental Health, Religion \& Culture. doi:10. $1080 / 13674676.2015 .1021312$.

Allport, G. W., \& Ross, J. M. (1967). Personal religious orientation and prejudice. Journal of Personality and Social Psychology, 5, 432-443.

Altemeyer, B., \& Hunsberger, B. (1992). Authoritarianism, religious fundamentalism, quest, and prejudice. The International Journal for the Psychology of Religion, 2, 113-133.

American Psychiatric Association. (1994). Diagnostic and statistical manual of mental disorders (4th ed.). Washington, DC: American Psychological Association.

Barton, Y. A., Miller, L., Wickramaratne, P., Gameroff, M. J., \& Weissman, M. (2013). Religious attendance and social adjustment as protective against depression: A 10-year prospective study. Journal of Affective Disorders, 146(1), 53-57.

Bartz, J. D., Richards, P. S., Smith, T. B., \& Fisher, L. (2010). A 17-year longitudinal study of religion and mental health. Mental Health, Religion \& Culture, 13(7), 683-695. doi:10.1080/13674670801944966.

Batson, C. D., Schoenrade, P., \& Ventis, W. C. (1993). Religion and the individual: A social-psychological perspective. New York: Oxford University Press. 
Batson, C. D., \& Ventis, W. L. (1982). The religious experience: A social-psychological perspective. New York: Oxford.

Beck, A. T. (1976). Cognitive therapy and the emotional disorders. New York: International Universities Press.

Benson, P. L., Roehlkerpartain, E. C., \& Scales, P. C. (2012). Spirituality and positive youth development. In L. Miller (Ed.), The Oxford handbook of psychology and spirituality (pp. 468-485). New York, NY: Oxford University Press.

Berdnt, D. J. (1990). Inventories and scales. In B. B. Wolman (Ed.), Depressive disorders: Facts, theories an treatment methods (pp. 255-274). New York: John Wiley and Sons.

Bergin, A. E. (1983). Religiosity and mental health: A critical reevaluation and meta-analysis. Professional Psychology: Research and Practice, 14, 170-184.

Bergin, A. E., Masters, K. S., \& Richards, P. S. (1987). Religiousness and mental health reconsidered: A study of an intrinsically religious sample. Journal of Counseling Psychology, 34, 197-204.

Bergin, A. E., Stinchfield, R. D., Gaskin, T. A., Masters, K. S., \& Sullivan, C. E. (1988). Religious life styles and mental health: An exploratory study. Journal of Counseling Psychology, 35, 91-98.

Berrett, M. E., Hardman, R. K., \& Richards, P. S. (2010). The role of spirituality in eating disorder treatment and recovery. In M. Maine, D. Bunnell, \& B. McGilley (Eds.), Special issues in the treatment of eating disorders: Bridging the gaps (pp. 367-385). Maryland Heights, MO: Elsevier.

Brewczynski, J., \& MacDonald, D. A. (2006). Confirmatory factor analysis of the Allport and Ross religious orientation scale with a polish sample. The International Journal for the Psychology of Religion, 16(1), 63-76.

Broday, S. F. (1988). A shortened version of the burns perfectionism scale. Psychological Reports, 62, 70.

Burns, D. D. (1980). The perfectionist's script for self-defeat. Psychology Today, 14(6), 34-52.

Burroughs, J. E., \& Rindfleisch, A. (2002). Materialism and well-being: A conflicting values perspective. Journal of Consumer Research, 29, 348-370.

Cochran, C. D., \& Hale, W. Daniel. (1985). College student norms on the brief symptom inventory. Journal of Clinical Psychology, 41, 777-779.

Derogatis, L. R., \& Melisaratos, N. (1983). The brief symptom inventory: An introductory report. Psychological Medicine, 13, 595-605.

Desrosiers, A., \& Miller, L. (2007). Relational spirituality and depression in adolescent girls. Journal of Clinical Psycholology, 63, 1021-1037.

Donahue, M. J. (1985). Intrinsic and extrinsic religiousness: Review and meta-analysis. Journal of Personality and Social Psychology, 48, 400-419.

Edgington, S., Richards, P. S., Erickson, M. J., Jackson, A. P., \& Hardman, R. K. (2008). Perceptions of Jesus Christ's atonement among Latter-day Saint women with eating disorders and perfectionism. Issues in Religion and Psychotherapy, 32, 25-39.

Epstein, S. (1980). The self-concept: A review and the proposal of an integrated theory of personality. In E. Staub (Ed.), Personality: Basic aspects and current research (pp. 81-132). Englewood Cliffs, NJ: Prentice-Hall.

Epstein, S., \& O’Brien, E. J. (1983). The Multidimensional Self-esteem Inventory. Odessa, FL: Psychological Assessment Resources.

Fegg, M. J., Kramer, M., L'hoste, S., \& Borasio, G. D. (2008). The Schedule for Meaning in Life Evaluation (SMiLE): Validation of a new instrument for meaning-in-life research. Journal of Pain and Symptom Management, 35(4), 356-364.

Frankl, V. (1966). Self-transcendence as a human phenomenon. Journal of Humanistic Psychology, 6, 97-106.

Fullerton, J. T., \& Hunsberger, B. (1982). A unidimensional measure of Christian orthodoxy. Journal for the Scientific Study of Religion, 21, 317-326.

Garfinkel, P. E., \& Garner, D. M. (1982). Anorexia nervosa: A multidimensional perspective. New York: Brunner/Mazel.

Garner, D. M., \& Garfinkel, P. E. (1979). The eating attitudes test: An index of the symptoms of anorexia nervosa. Psychological Medicine, 9, 273-279.

Gartner, J. (1983). Self-esteem tests: Assumptions and values. In C. Ellison (Ed.), Your better self: Psychology, Christianity and self-esteem. New York: Harper \& Row.

Gartner, J., Larson, D. B., \& Allen, G. D. (1991). Religious commitment and mental health: A review of the empirical literature. Journal of Psychology and Theology, 19, 6-25.

Genia, V. (1993). A psychometric evaluation of the Allport-Ross I/E scales in a religiously heterogeneous sample. Journal for the Scientific Study of Religion, 32, 284-290.

Glock, C. Y., \& Stark, R. (1966). Christian beliefs and anti-semitism. New York: Harper \& Row. 
Heise, R. G., \& Steitz, J. A. (1991). Religious perfectionism versus spiritual growth. Counseling and Values, $36,11-23$.

Hewitt, P. L., Flett, G. L., Turnbull-Donovan, W., \& Mikail, S. F. (1991). The multidimensional perfectionism scale: Reliability, validity, and psychometric properties in psychiatric samples. Psychological Assessment, 3, 464-468.

Koenig, H. G., McCullough, M. E., \& Larson, D. B. (2001). Handbook of religion and health. New York: Oxford University Press.

Maloney, H. N. (1988). The assessment of optimal religious functioning. Review of Religious Research, 30, 3-17.

Maloney, H. N. (1994). Theological functioning and mental health. In V. Demarinis \& O. Wickstrom (Eds.), the clinical psychology of religion, emerging cultural and multicultural questions from European and American voices (pp. 18-26). Upsela: Swedish Council of Research.

Maslow, A. H. (1971). The farther reaches of human nature. New York, NY: Penguin.

Matthews, E. E., \& Cook, P. F. (2009). Relationships among optimism, well-being, self-transcendence, coping, and social support in women during treatment for breast cancer. Psycho-Oncology, 18(7), 716-726.

McFarland, S. G. (1989). Religious orientations and the targets of discrimination. Journal for the Scientific Study of Religion, 28, 324-336.

Mebane, D. L., \& Ridley, C. R. (1988). The role-sending of perfectionism: Overcoming counterfeit spirituality. Journal of Psychology and Theology, 16, 332-339.

Miller, L. (2015). The spiritual child: The new science on parenting for health and lifelong thriving. New York, NY: St. Martin's Press.

Miller, L., Davies, M., \& Greenwald, S. (2000). Religiosity and substance use and abuse among adolescents in the national comorbidity survey. Journal of the American Academy of Child and Adolescent Psychiatry, 39, 1190-1197.

Miller, W. R., \& Thoresen, C. E. (2003). Spirituality, religion, and health. American Psychologist, 58, 24-35.

Miller, L., Warner, V., Wickramaratne, P., \& Weissman, M. (1997). Religiosity and depression: Ten-year follow-up of depressed mothers and offspring. Journal of the American Academy of Child and Adolescent Psychiatry, 36, 1416-1425.

Payne, I. R., Bergin, A. E., Bielema, K. A., \& Jenkins, P. H. (1991). Review of religion and mental health: Prevention and the enhancement of psychosocial functioning. Prevention in Human Services, 9, 11-40.

Ramer, L., Johnson, D., Chan, L., \& Barrett, M. T. (2006). The effect of HIV/AIDS disease progression on spirituality and self-transcendence in a multicultural population. Journal of Transcultural Nursing, 17(3), 280-289.

Reed, P. G. (1991). Self-transcendence and mental health in oldest-old adults. Nursing Research, 40, 5-11.

Richards, P. S. (1991). Religious devoutness in college students: Relations with emotional adjustment and psychological separation from parents. Journal of Counseling Psychology, 38, 189-196.

Richards, P. S. (1994). Religious devoutness, impression management, and personality functioning in college students. Journal of Research in Personality, 28, 14-26.

Richards, P. S., \& Bergin, A. E. (2005). A spiritual strategy for counseling and psychotherapy (2nd ed.). Washington, DC: American Psychological Association.

Richards, P. S., \& Bergin, A. E. (2014). Religious diversity and psychotherapy: Conclusions, recommendations, and future directions. In P. S. Richards \& A. E. Bergin (Eds.), Handbook of psychotherapy and religious diversity (2nd ed., pp. 475-487). Washington, DC: American Psychological Association.

Richards, P. S., \& Davison, M. L. (1992). Religious bias in moral development research: A psychometric investigation. Journal for the Scientific Study of Religion, 31, 467-485.

Richards, P. S., Owen, L., \& Stein, S. (1993). A religiously oriented group counseling intervention for selfdefeating perfectionism: A pilot study. Counseling and Values, 37, 96-104.

Richards, P. S., Smith, S. A., \& Davis, L. F. (1989). Healthy and unhealthy forms of religiousness manifested by psychotherapy clients: An empirical investigation. Journal of Research in Personality, 23, 506-524.

Rokeach, M. (1960). The open and closed mind. New York: Basic Books, Inc.

Spielberger, C. D., Gorsuch, R. L., Lushene, R. E., Vagg, P. R., \& Jacobs, G. A. (1983). Manual for the state-trait anxiety inventory. Palo Alto, CA: Mind Garden.

Steger, M. F., Fraizer, P., Oishi, S., \& Kaler, M. (2006). The meaning in life questionnaire: Assessing the presence of search for meaning in life. Journal of Counseling Psychology, 53, 80-93.

Strommen, M. P. (Ed.). (1971). Research on religious development: A comprehensive handbook. New York: Hawthorn. 
Tangney, J. P., Burggraf, S. A., \& Wagner, P. E. (1995). The psychology of shame, guilt, embarrassment, and pride. New York: Guilford.

Tangney, J. P., Wagner, P. E., \& Gramzow, R. (1989). The test of self-conscious affect. Fairfax, VA: George Mason University.

Thurstone, N. S. (1998). Psychotherapy with members of Evangelical and Fundamentalist Protestant Churches. In P. S. Richards \& A. E. Bergin (Eds.), Handbook of psychotherapy and religious diversity: A guide for mental health professionals. Washington, DC: American Psychological Association.

Ulrich, W., Richards, P. S., Hansen, K. L., \& Bergin, A. E. (2014). Psychotherapy with Latter-day Saints. In P. S. Richards \& A. E. Bergin (Eds.), Handbook of psychotherapy and religious diversity (2nd ed., pp. 179-205). Washington, DC: American Psychological Association.

Watson, P. J., Hood, R. W., Morris, R. J., \& Hall, J. R. (1985). Religiosity, sin and self-esteem. Journal of Psychology and Theology, 13, 116-128.

Wilber, K. (2000). Integral psychology: Consciousness, spirit, psychology, therapy. Boston, MA: Shambhala.

Wulff, D. M. (1997). Psychology of religion: Classic and contemporary views (2nd ed.). New York: Wiley. 